https://doi.org/10.15407/ujpe65.6.480

N.E. KORNIENKO, O.L. PAVLENKO

Taras Shevchenko National University of Kyiv

(64/13, Volodymyrs'ka Str., Kyiv 01601, Ukraine)

\title{
MULTIPLE FERMI RESONANCES IN LIQUID BENZENE ${ }^{1}$
}

\begin{abstract}
A number of coupled Fermi vibrational resonances (FRs) in liquid benzene from a multitude of them are systematically studied. The spectral structure of the vibrational bands in the IR absorption and Raman scattering spectra are determined by their numerical decomposition into individual components. The complication of vibrational resonances with an increase in their order is due to the overlapping of FRs and the appearance of additional resonant vibrational modes. To clarify the identification of the vibrations of the benzene $F R \nu_{1}+\nu_{6}, \nu_{8}$ and the correction of the frequencies of a number of inactive vibrations, including $\nu_{13}\left(E_{1 u}\right)$, the experimental results are compared to the data obtained by quantum-chemical calculations. With regard for the collective-wave properties of vibrational modes in the benzene liquid state, we propose a new content of the analysis of FRs. It should include the study of 1) the intensity changes for various spectral components in the IR absorption and Raman scattering for FR vibrational bands of various orders, 2) half-widths $\delta \nu$ of the bands, and 3) anharmonic shifts $\Delta \nu_{A}$ for various components in the vibrational bands of FRs.

Ke ywords: multiple resonances, liquid benzene, IR absorption, Raman scattering spectra.
\end{abstract}

\section{Introduction}

Quantum properties of supramolecular structures (molecular clusters, liquids, solutions, etc.) have not been studied systematically till now. Quantumchemical calculations were carried out mostly for simple molecules and atoms, but the complex organic molecules and liquids are very important as well, especially carbon-based molecular structures and cyclic aromatic compounds. The delocalization of the electron structure in the aromatic compounds leads to their higher stability. Cyclic molecular structures are in the base of DNA, chlorophyll, and blood heme. Typical representatives of aromatic molecules are benzene $\mathrm{C}_{6} \mathrm{H}_{6}$ and its substituents (toluene $\mathrm{C}_{6} \mathrm{H}_{5} \mathrm{CH}_{3}$, xylene $\mathrm{C}_{6} \mathrm{H}_{4}\left(\mathrm{CH}_{3}\right)_{2}$, halogenated benzene $\mathrm{C}_{6} \mathrm{H}_{5} \mathrm{X}$ $(\mathrm{X}=\mathrm{F}, \mathrm{Cl}, \mathrm{Br}, \mathrm{J})$, pyridine $\mathrm{C}_{5} \mathrm{H}_{5} \mathrm{~N}$, nitrobenzene $\mathrm{C}_{6} \mathrm{H}_{5} \mathrm{NO}_{2}$, etc. Cyclic aromatic compounds are important in chemical technologies for the synthesis of dyes, biologically active compounds, liquid crystals, explosives, and others. The study of molecules is important for the development of fundamental science. For example, benzonitrile $\mathrm{C}_{6} \mathrm{H}_{5} \mathrm{CN}$ was detected in the interstellar space.

Benzene has been studied for more than 190 years, but a number of unresolved issues still remain. Li-

(C) N.E. KORNIENKO, O.L. PAVLENKO, 2020 quid benzene has a set of absorption bands that includes a multitude of total frequenies and overtones in the IR spectral range. Only $1 / 3$ of the total number of them are identified [1]. In particular, most of the vibration bands for liquid benzene $\mathrm{C}_{6} \mathrm{H}_{6}$ (even for nondegenerated vibrations) are multiplets, and this fact is not explained in details. Moreover, for a long time, a discussion has been going on about the exact determination of the frequencies in the IR absorption and Raman scattering spectra such as, for example, the frequencies $\nu_{13}\left(B_{1 u}\right)$, $\nu_{20}\left(E_{1 u}\right)$ before the resonant interaction with the total tones $\nu_{8}+\nu_{19}$ and $\left(\nu_{1}+\nu_{6}\right)+\nu_{19}$ [2]. It should be noted that the vibrational modes $(\mathrm{VM}) \nu_{1}+\nu_{6}$, $\nu_{8}\left(E_{2 g}\right)$ form the first Fermi resonance $R_{1}$, and the $\mathrm{VM}\left(\nu_{1}+\nu_{6}\right)+\nu_{19} \approx \nu_{8}+\nu_{19} \approx \nu_{20}$ - the second Fermi resonance $R_{2}\left(\nu_{20}, R_{1}+\nu_{19}\right)$, which is connected with the first one. All 30 normal vibrations of an isolated molecule $\mathrm{C}_{6} \mathrm{H}_{6}$ are classified as $\Gamma_{v}=2 A_{1 g}+A_{2 g}+$ $+A_{2 u}+2 B_{2 g}+2 B_{1 u}+2 B_{2 u}+E_{1 g}+3 E_{1 u}+4 E_{2 g}+2 E_{2 u}$ (10 nondegenerated ones of the $A$ and $B$ types and 10 twofold degenerated vibrations of the $E$ type ) of the $D_{6 h}$ symmetry group.

1 The paper was presented at the XXIVth Galyna Puchkovska International School-Seminar "Spectroscopy of Molecules and Crystals" (August 25-30, 2019, Odesa, Ukraine).

ISSN 2071-0194. Ukr. J. Phys. 2020. Vol. 65, No. 6 


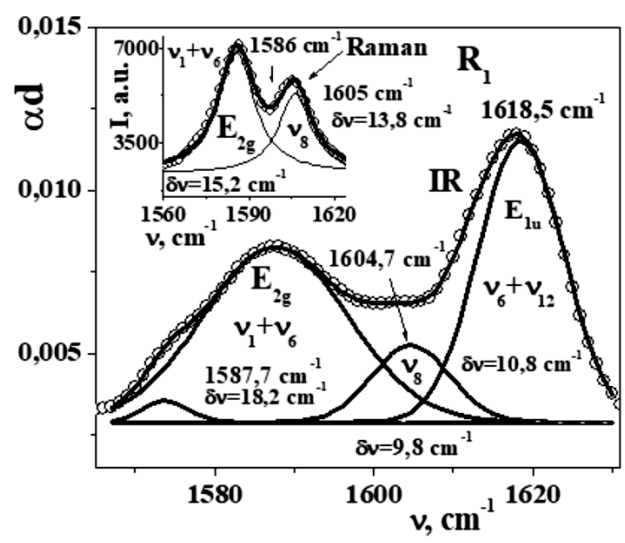

$a$

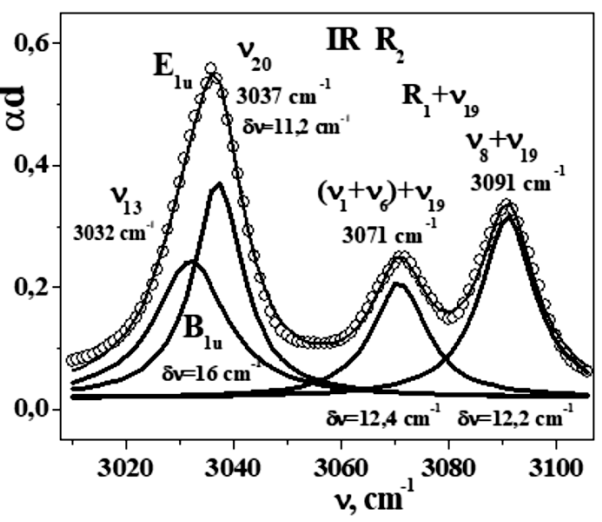

$b$

Fig. 1. Results of the decomposition of the observed IR bands of liquid benzene at room temperature in the Fermi resonance regions $R_{1}(a)$ and $R_{2}(b)$, as well as in the Raman spectrum (inset), into individual components of the Lorentzian form

Here, with a bold-type font, we designate active vibrations in the vibrational spectra $\left(A_{1 g}, E_{1 g}\right.$ and $E_{2 g}$ are Raman active vibrations, $A_{2 u}, E_{1 u}$ are IRactive ones). On the whole, $45 \%$ of the vibrational frequencies of a benzene molecule are not active in the IR absorption and Raman spectra ("silent" vibrations). This fact and the presence of complex Fermi resonances complicate the interpretation of vibrational spectra and the accompanying physical and chemical processes.

The main difficulties in the vibrational spectra of liquid benzene are associated with its liquid state, where the collective properties of vibrational modes are manifested [3-13]. It is essential that the thermal excitation of vibration modes in liquids exceeds the critical level $[14,15]$ for the appearance of nonlinearly-wave interactions of vibration bands $[16-18]$. The last ones lead to a non-equilibrium population of higher vibrational states (overtones ant total tones), by shifting them to the level of electron states. Therefore, the vibration-electron interaction (VEI) appears and induces new electronic states which are observed in the form of a broadband background in the vibrational spectra and in the change of chemical bonds [19-21]. The phenomenon of VEI is substantially amplified in the presence of the array of interconnected vibrational-wave resonances [22, 23] and the nonlinearly-wave interaction of vibration modes is amplified as well. Here, we demonstrate the existence of multiple Fermi vibrational resonances with a complicated structure of vibrational bands for liquid benzene. For the correct identification of resonant vibration modes, we compare the experimental data with the results of quantum chemical calculations.

\section{Contradictions in Identification} of Vibrational Modes in Two Initial Fermi Resonances of Liquid Benzene

P. Krishnamurti and R. Ananthakrishnan [24] showed convincingly that, in the Raman spectra (RS) of liquid benzene in the observed doublet of vibrational bands $1584-1585$ and $1604-1606 \mathrm{~cm}^{-1}$, the low-frequency component is more intense by 1.5 times. This is illustrated by the inset in Fig. 1, $a$, which shows a fragment of the RS in the region of the first Fermi resonance $R_{1}$ between the fundamental vibration $\nu_{8}$ and the total tone $\nu_{1}+\nu_{6}$ with a calculated frequency of $992+606=1598 \mathrm{~cm}^{-1}$. Since the low-frequency component of about $1586 \mathrm{~cm}^{-1}$ was more intense, it was naturally assumed that it has the predominant contribution of the fundamental mode $\nu_{8}$. It was believed so for a long time, despite the completely different picture in the region of the second Fermi resonance $R_{2}\left(\nu_{20}, R_{1}+\nu_{19}\right)$, which is observed in the IR spectrum (see Fig. 1, b).

In this region, the Fermi resonance $R_{1}$ shifted by the frequency of active vibrations $\nu_{19}\left(E_{1 u}\right)=$ $=1479 \mathrm{~cm}^{-1}$ into the high-frequency $(\mathrm{HF})$ region resonates with $\nu_{20}\left(E_{1 u}\right)$ which is the most intense in the IR spectrum. Taking the frequency values observed in the region of $R_{1} 1586$ and $1605 \mathrm{~cm}^{-1}$ into account, we find the calculated values in the region 


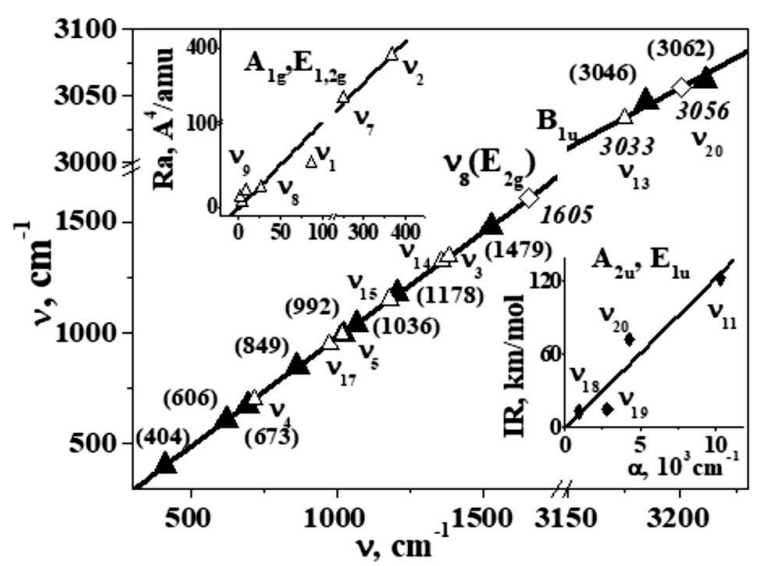

Fig. 2. Vibrational frequencies of a $\mathrm{C}_{6} \mathrm{H}_{6}$ molecule. Correlations of the calculated and the experimental vibrational frequencies of liquid benzene

of $R_{2} 3065 \mathrm{~cm}^{-1}$ and $3084 \mathrm{~cm}^{-1}$. The observed frequency values are shifted to the HF side by 6 and $7 \mathrm{~cm}^{-1}$ due to the resonant interaction with the vibration $\nu_{20}$. In contrast to the bands $\nu_{1}+\nu_{6}, \nu_{8}$ in the Raman spectrum (see insert $1, a$ ) in $R_{1}+\nu_{19}$, the more intense component is at $3091 \mathrm{~cm}^{-1}$ (Fig. 1, b). The high-frequency component should be identified with the total tone $\nu_{8}+\nu_{19}$ associated with the fundamental vibration mode $\nu_{8}$. As a result, we come to a clear contradiction in the interpretation of the vibrational bands observed in the regions of two coupled Fermi resonances $R_{1}$ and $R_{2}$. Moreover, the observed components at 1595 and $1605 \mathrm{~cm}^{-1}$ (in the Raman spectrum of $\mathrm{C}_{6} \mathrm{H}_{5} \mathrm{OH}$ in the $R_{1}$ region) have equal intensities [24], and, in the observed resonant doublet of toluene at 1588 and $1606 \mathrm{~cm}^{-1}$, the high-frequency component is in 1.5 times more intensive, contributed from vibration mode $\nu_{8}$. This shows the difficulty to identify the vibration modes, by basing on the observed intensities of the spectral components. It should be noted that, in an isotopically substituted ${ }^{13} \mathrm{C}_{6} \mathrm{H}_{6}$ molecule $\left(1.1 \%\right.$ of ${ }^{13} \mathrm{C}$ isotope is present in nature), a completely different picture is observed in the IR spectrum [2]: vibrations $\left(\nu_{1}+\nu_{6}\right)+\nu_{19}$ and $\nu_{8}+\nu_{19}$ are in the low-frequency region (2993 and $\left.3005 \mathrm{~cm}^{-1}\right)$, and the frequency $\nu_{20}=3054 \mathrm{~cm}^{-1}$ is in the high-frequency region. This is due to a decrease in the frequency of skeletal vibrations $\nu_{1}, \nu_{6}$ and $\nu_{8}$, a small change in the frequency of $\mathrm{CH}$ vibrations $\nu_{20}$, and a significant weakening of the Fermi resonance.

We performed the additional studies of the observed Fermi resonances in liquid benzene, includ- ing the quantum chemical calculations for a ${ }^{12} \mathrm{C}_{6} \mathrm{H}_{6}$ molecule, as well as the experimental study of higher Fermi resonances. The vibrations $\nu_{1}+\nu_{6}, \nu_{8}$ of symmetry $E_{2 g}$ in the IR spectrum of a molecule $\mathrm{C}_{6} \mathrm{H}_{6}$ are not allowed, but they appear in liquid benzene as the total tone $\nu_{6}+\nu_{12}$ of the symmetry $E_{1 u}$, as shown in Fig. 1, $a$. The correctness of the decomposition of the resonance $\nu_{1}+\nu_{6}, \nu_{8}$ was controlled by the agreement of the second derivatives of the observed and calculated vibrations. As a result, the high-frequency component at $1604.7 \mathrm{~cm}^{-1}$ has lower intensity and can be attributed to the vibration $\nu_{8}$, since the selection rules can be easily violated for the composite tones. Moreover, the component has a smaller half-width $\delta \nu=9.8 \mathrm{~cm}^{-1}$, which is two times less than the half-width of the other component at $1587.7 \mathrm{~cm}^{-1}$. Therefore the high-frequency component at $1604.7 \mathrm{~cm}^{-1}$ is related to the main vibration $\nu_{8}$, which is consistent with the analysis of the second Fermi resonance $R_{2}\left(\nu_{20}, R_{1}+\nu_{19}\right)$ in Fig. 1, $b$.

\section{Quantum-Mechanical Calculations} of a Benzene Molecule and Clarification of the Frequencies for the Row of Vibrations

To clarify the frequencies of fundamental vibrations $\nu_{8}\left(E_{2 g}\right)$ and $\nu_{20}\left(E_{1 u}\right)$ taking part in the Fermi resonances $R_{1}\left(\nu_{1}+\nu_{6}, \nu_{8}\right)$ and $R_{2}\left(\nu_{20}, R_{1}+\nu_{19}\right)$, the quantum-chemical calculations were carried out for a $\mathrm{C}_{6} \mathrm{H}_{6}$ molecule. In this case, the density functional B3LYP and bases 6-311G(d,p), 6-311++G(d,p) were used. Then the calculated frequencies of all oscillations were scaled using the experimental values for vibration frequencies active in the IR absorption $\left(\nu_{11}\right.$, $\nu_{18}$ and $\left.\nu_{19}\right)$ and Raman spectra $\left(\nu_{1}, \nu_{2}, \nu_{6}, \nu_{7}, \nu_{9}\right.$ and $\left.\nu_{10}\right)$, as illustrated in Fig. 2. Experimentally obtained frequencies are in the parentheses (dark symbols), including the low-frequency "silent" oscillation $\nu_{16}=404 \mathrm{~cm}^{-1}$ (Raman spectrum). In this case, the $\nu_{8}$ and $\nu_{20}$ oscillations, which are significantly displaced due to Fermi resonances, as well as most of the "silent" oscillations, were excluded from the experimental basis of frequencies. The dependence of the experimental frequency values on the calculated values was approximated by a polynomial of degree 3 . With its help, the values of $\nu_{8}$ and $\nu_{20}$ were refined without accounting for their resonant interactions, as well as inactive vibrations.

ISSN 2071-0194. Ukr. J. Phys. 2020. Vol. 65, No. 6 


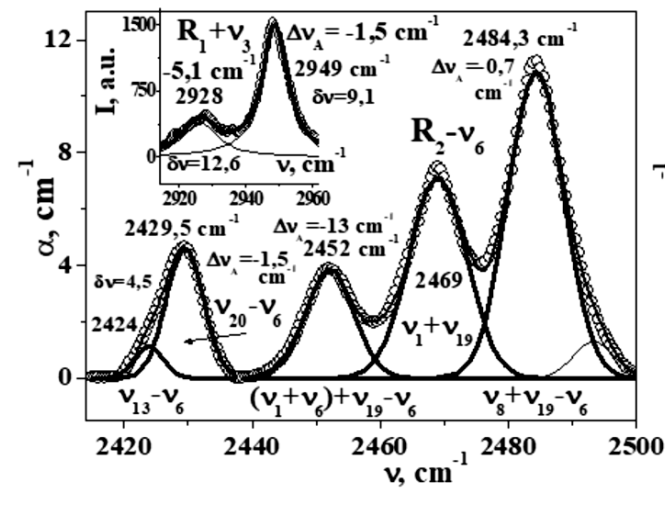

$a$

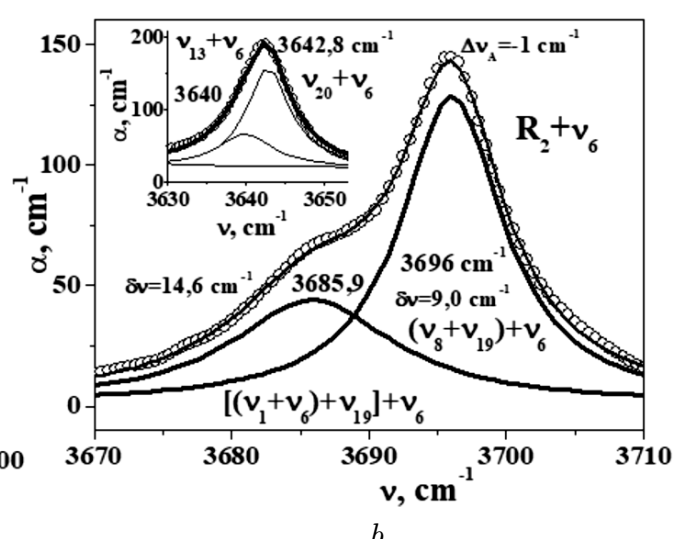

$b$

Fig. 3. Selected IR absorption bands of liquid benzene in the region of Fermi resonances of 3-4 orders of magnitude $R_{2}-\nu_{6}(a)$ and $R_{2}+\nu_{6}(b)$, as well as the resonance bands $R_{1}+\nu_{3}$ in the Raman spectrum (inset in Fig. $a$ ) and the results of their numerical decomposition into individual spectral components

The calculated frequencies of "silent" oscillations $\nu_{4}=701 \mathrm{~cm}^{-1}, \nu_{5}=988 \mathrm{~cm}^{-1}$, and $\nu_{3}=1343 \mathrm{~cm}^{-1}$ are in good agreement with the generally accepted values of these frequencies 703,989 , and $1346 \mathrm{~cm}^{-1}$ that characterizes the accuracy of the method. The obtained frequencies of $\nu_{8}$ and $\nu_{20}$ are 1605 and $3056 \mathrm{~cm}^{-1}$, respectively, Fig. 2. The frequency of $\nu_{13}\left(B_{1 u}\right)$ vibration is at $3033 \mathrm{~cm}^{-1}$. The frequencies are indicated by bright symbols in Fig. 2. The band $\nu_{13}\left(B_{1 u}\right)=3032 \mathrm{~cm}^{-1}$ is observed in the lowfrequency wing of the strong IR band $\nu_{20}\left(E_{1 u}\right)=$ $=3037 \mathrm{~cm}^{-1}$, Fig. 1, $b$. The interpretation of the bands is confirmed in higher-order Fermi resonance bands considered in the next section.

The calculated frequency of $\nu_{8}\left(E_{2 g}\right)=1605 \mathrm{~cm}^{-1}$ is exactly equal to the observed Raman component in the region $R_{1}$, the inset in Fig. $1, a$. This is consistent with the IR spectrum in the second resonance region, Fig. 1, b. A similar scaling of the frequencies of the quantum-mechanical calculation was carried out using experimental frequencies for gaseous benzene. The following frequencies were obtained: $\nu_{8}^{*}=1608.5 \mathrm{~cm}^{-1}, \nu_{13}^{*}=3044 \mathrm{~cm}^{-1}$ and $\nu_{20}^{*}=3053 \mathrm{~cm}^{-1}$. A higher frequency $\nu_{8}^{*}$ for benzene vapors, as well as the frequencies $\nu_{1}^{*}=993 \mathrm{~cm}^{-1}$ and $\nu_{6}^{*}=608 \mathrm{~cm}^{-1}\left(\nu_{1}^{*}+\nu_{6}^{*}=1601 \mathrm{~cm}^{-1}<\nu_{8}^{*}\right)$, additionally confirm the correctness of our assignment of frequencies in the region of the main Fermi resonance in benzene. Correlations of the observed integrated intensities of the bands in the Raman spectra and the calculated activities Ra of these bands (upper inset), as well as the correlations of the peak absorption coefficients $\alpha$ for the IR bands and the calculated values (lower inset) are presented in Fig. 2.

\section{Higher-Order Fermi}

Resonances in Benzene and New Principles for the Identification of Vibrations in Fermi Resonances

Analogously to the formation of the second Fermi resonance of $R_{2}\left(\nu_{20}, R_{1}+\nu_{19}\right)$ from the vibrational resonance $R_{1}\left(\nu_{1}+\nu_{6}, \nu_{8}\right)$, by combinations of these resonances with other vibrations, the large plurality of vibrational resonances is formed. As an example, Fig. 3 shows the vibrational bands selected in the IR spectra of liquid benzene in the Fermi resonance regions $R_{2} \pm \nu_{6}$. The observed Fermi resonances in the liquid state of a substance are significantly different from Fermi resonances in isolated molecules. This is due to that the vibrational modes (VMs) in liquids have wave properties and, due to the spatiotemporal accumulation of nonlinear resonance wave processes, the intensities of the corresponding vibrational bands change in an unpredictable way. In particular, in Fig. 3, $a$, the second-order band $\nu_{20}-\nu_{6}$ has a smaller intensity, than the HF band of the 3rd order $\left(\nu_{8}+\nu_{19}\right)-\nu_{6}$. However, the cognate Fermi resonance of $R_{2}+\nu_{6}$ in Fig. $3, b$ IR band $\nu_{20}+\nu_{6}=3642.8 \mathrm{~cm}^{-1}$ (shown as the inset) has the maximum intensity as the band of IR $\nu_{20}$ in Fig. $1, b$.

In the region of the summary tone, $R_{2}-\nu_{6}$ penetrates additional $\nu_{1}+\nu_{19}=2469 \mathrm{~cm}^{-1}$ (calculated 


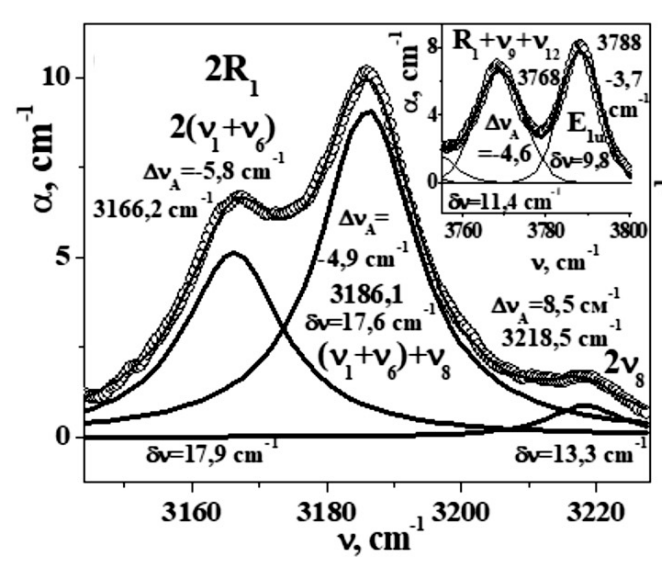

$a$

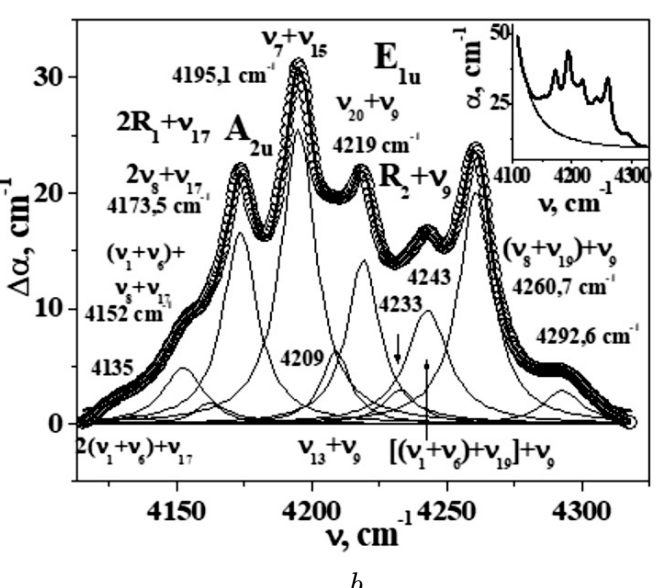

b

Fig. 4. IR absorption bands of liquid benzene in the region of Fermi resonances of $2-5$ orders of magnitude $2 R_{1}$ and $R_{1}+\nu_{9}+\nu_{12}(a), 2 R_{1}+\nu_{17}, R_{2}+\nu_{9}$ and strong oscillations $\nu_{7}+\nu_{5}(b)$ and the results of their numerical decomposition into individual components of the Lorentzian form

frequency equals $2470 \mathrm{~cm}^{-1}$ ) with the same symmetry $E_{1 u}$, which complicates this Fermi resonance (FR), Fig. 3, $a$. Note that the additional oscillation $\nu_{1}+\nu_{19}$ significantly changes the FR. If, in the resonances $R_{1}$ in Fig. 1, $a$, the frequency splitting is $\Delta \nu=\nu_{8}-$ $-\left(\nu_{1}+\nu_{6}\right)=17-19 \mathrm{~cm}^{-1}$, and, in the region $R_{2}, \Delta \nu=$ $=20 \mathrm{~cm}^{-1}$, then, in the resonance region $R_{2}-\nu_{6}$, the value of $\Delta \nu$ increases to $32.3 \mathrm{~cm}^{-1}$. At the same time, in the region of $R_{2}+\nu_{6}$, the value is $\Delta \nu \approx 10 \mathrm{~cm}^{-1}$. In this case, the total spectral width of the resonances $R_{2}$ and $R_{2} \pm \nu_{6} \Delta \nu^{\prime}=\left(\nu_{8}+\nu_{19}\right)-\nu_{20}$ is kept quite constant and equal to $53-54 \mathrm{~cm}^{-1}$. It is remarkable that, in the bands $\nu_{20} \pm \nu_{6}$ in Fig. 3, $a, b$ in the asymmetric low-frequency wings, the additional components $\nu_{13} \pm$ $\pm \nu_{6}$ with frequencies of 2424 and $3640 \mathrm{~cm}^{-1}$ are well manifested. Knowing the frequency $\nu_{6}=606 \mathrm{~cm}^{-1}$, we found the frequencies $\nu_{13}=3030$ and $3034 \mathrm{~cm}^{-1}$, which are in good agreement with the values of 3032 and $3033 \mathrm{~cm}^{-1}$ observed in Fig. 1, $b$ and determined by the scaling of the frequencies of quantum-chemical calculations. Thus, we have established the frequency of the "silent" oscillation $\nu_{13}\left(B_{1 u}\right)=3032 \mathrm{~cm}^{-1}$, although, even in the recent detailed work [1], it is attributed to the value $3057.2 \mathrm{~cm}^{-1}$, and, in [2], the value of $3062 \mathrm{~cm}^{-1}$ is accepted.

The inset in Fig. 3, $a$ shows a fragment of the Raman spectrum in the resonance region $R_{1}+\nu_{3}$ (symmetry $E_{2 g}$ ). In this case, the main Fermi resonsnce $\nu_{1}+\nu_{6}, \nu_{8}$ shifts into the HF region by the frequency of "silent" oscillations $\nu_{3}\left(A_{2 g}\right)=1346 \mathrm{~cm}^{-1}$. The intensity of the HF band $\nu_{8}+\nu_{3}=2949-2950 \mathrm{~cm}^{-1}$ sig- nificantly exceeds the band intensity $\left(\nu_{1}+\nu_{6}\right)+\nu_{3}=$ $=2928 \mathrm{~cm}^{-1}$, which is a significant confirmation of the earlier assignment of vibrational bands in the FR $R_{1}$ and $R_{2}$. It should be noted that the intensity of the $\nu_{8}+\nu_{3}$ band in the considered resonance $R_{1}+\nu_{3}$ is approximately the same as the main band $\nu_{8}$ (see the inset in Fig. 1, a). Thus, for all the above four Fermi resonances $R_{2}, R_{2} \pm \nu_{6}$ and $R_{1}+\nu_{3}$, the intensity of the $\mathrm{HF}$ components related to the fundamental vibration $\nu_{8}$ is dominant. A similar situation occurs in the region of $R_{1}+\nu_{9}+\nu_{12}$ of the IR spectrum, which is illustrated in the inset of Fig. 4, $a$. Despite the participation of the "silent" vibration $\nu_{12}\left(B_{1 u}\right)=1008 \mathrm{~cm}^{-1}$ in this combination due to the general symmetry $E_{1 u}$, this resonance appears in the IR spectrum.

The interesting situation is observed in the region of the overtone of the first Fermi resonance $2 R_{1}$, as shown in Fig. 4, a. Despite the symmetry of $E_{2 g}$, this resonance region is clearly manifested in the IR spectrum due to the violation of the strict selection rules for isolated molecules for the liquid state. In this case, the maximum intensity is observed for the total tone $\left(\nu_{1}+\nu_{6}\right)+\nu_{8}$. The abnormally low intensity is typical of the envelope of $2 \nu_{8}$. This indicates the strengthening of chemical bonds in an excited vibrational state. It is well known that the intensity of overtones increases with the anharmonicity. In single crystals with strong covalent bonds, the intensity of overtones is very low.

The complication of multiwave overlapping Fermi resonances is shown in Fig. $4, b$. This complex IR 
Half-widths of the spectral components $\delta \nu\left(\right.$ in $\left.\mathrm{cm}^{-1}\right)$ associated with the fundamental vibration $\nu_{8}$ and the total tone $\nu_{1}+\nu_{6}$ for a number of vibrational resonances

\begin{tabular}{|c|c|c|c|c|c|c|}
\hline $\begin{array}{c}\text { Fermi } \\
\text { resonance }\end{array}$ & \multicolumn{2}{|c|}{$R_{1}$} & $R_{1}+\nu_{3}$ & $R_{2}$ & $R_{1}+\nu_{6}$ & $2 R_{1}$ \\
\hline $\begin{array}{c}\text { Vibration } \\
\text { mode }\end{array}$ & $\begin{array}{c}\text { Raman } \\
\text { spectrum }\end{array}$ & $\begin{array}{c}\text { IR } \\
\text { spectrum }\end{array}$ & $\begin{array}{c}\text { Raman } \\
\text { spectrum }\end{array}$ & $\begin{array}{c}\text { IR } \\
\text { spectrum }\end{array}$ & $\begin{array}{c}\text { IR } \\
\text { spectrum }\end{array}$ & $\begin{array}{c}\text { IR } \\
\text { spectrum }\end{array}$ \\
\hline$\nu_{8}$ & 13.8 & 9.8 & 9.1 & 12.2 & 9.0 & 13.3 \\
$\nu_{1}+\nu_{6}$ & 15.2 & 18.2 & 12.6 & 12.4 & 14.6 & 17.9 \\
\hline
\end{tabular}

band on the high-frequent wing of a more intense band is shown in the inset in Fig. $4, b$. Here, the vibrational resonances $2 R_{1}+\nu_{17}$ and $R_{2}+\nu_{9}$ are superimposed, and the total tone $\nu_{7}+\nu_{15}$ is added to them. Despite the participation of "silent" oscillations $\nu_{17}\left(E_{2 u}\right)=966 \mathrm{~cm}^{-1}$ and $\nu_{15}\left(B_{2 u}\right)=1149 \mathrm{~cm}^{-1}[2]$ in these Fermi resonances, according to the rules for multiplying the irreducible representations, the final symmetries of the oscillations $2 R_{1}+\nu_{17}$ and $\nu_{7}+\nu_{15}$ are $A_{2 u}$ and $E_{1 u}$, respectively. The identical symmetry $E_{1 u}$ of the vibrations $\nu_{7}+\nu_{15}$ and $R_{2}+\nu_{9}$ leads to their additional interaction. This is manifested in a decrease in the splitting $\Delta \nu$ between the oscillations $\left(\nu_{8}+\nu_{19}\right)+\nu_{9}$ and $\left[\left(\nu_{1}+\nu_{6}\right)+\nu_{19}\right]+\nu_{9}$ from 20 to $17.7 \mathrm{~cm}^{-1}$, as well as a decrease in the total splitting $\Delta \nu^{\prime}$ resonance $R_{2}+\nu_{9}$ from $53-54 \mathrm{~cm}^{-1}$ to $41.7 \mathrm{~cm}^{-1}$. The changes in the intensity distribution in the bands $2 R_{1}$ in Fig. $4, a$ and $2 R_{1}+\nu_{17}$ (Fig. $4, b$ ) indicates a possible interaction of the vibrations $2 R_{1}++\nu_{17}$ and $\nu_{7}+\nu_{15}, R_{2}+\nu_{9}$ despite the difference in their symmetry $\left(A_{2 u}\right.$ and $\left.E_{1 u}\right)$. The component $2 \nu_{8}+\nu_{17}=4173.5 \mathrm{~cm}^{-1}$ is amplified, which corresponds to the minimum intensity in Fig. 4, probably, due to the proximity to the strongest IR line $\nu_{7}+\nu_{15}=4195.1 \mathrm{~cm}^{-1}$, which almost is not shifted relative to the calculated value of $3046+1149=$ $=4195 \mathrm{~cm}^{-1}$.

In addition to the intensities of the spectral components, for correct identification, the important role is played by the analysis of the half-widths $\delta \nu$ of individual components and their anharmonic shifts $\Delta \nu_{A}$ (differences of the observed and calculated frequencies). For the analyzed set of Fermi resonances, large $\delta \nu$ values have low-frequency components associated with composite tones $\nu_{1}+\nu_{6}$, which are characterized by the accelerated vibrational relaxation. Table shows the half-widths $\delta \nu$ for the spectral components of various Fermi resonances associated with the fundamental vibration $\nu_{8}$ and the total tone $\nu_{1}+\nu_{6}$. The lower half-widths $\delta \nu$ are characteristic of the main oscillation $\nu_{8}$ or the total difference tones with the participation of $\nu_{8}$.

Components with the participation of the total tones $\nu_{1}+\nu_{6}$ in addition to large half-widths $\delta \nu$ are characterized by large values of negative anharmonic shifts $\left(\Delta \nu_{A}<0\right)$. For example, for the low-frequency components $\left[\left(\nu_{1}+\nu_{6}\right)+\nu_{19}\right]-\nu_{6}=2452 \mathrm{~cm}^{-1}$ of the multiplet $\left(R_{1}+\nu_{19}\right)-\nu_{6}$, the anharmonic displacement is $\Delta \nu_{A}=-13.5 \mathrm{~cm}^{-1}$. The anharmonic displacement for the component $\left(\nu_{8}+\nu_{9}\right)-\nu_{6}=$ $=2484.3 \mathrm{~cm}^{1}$ is $\left(\Delta \nu_{A}=-0.7 \mathrm{~cm}^{-1}\right)($ Fig. 3, a). In the Raman region of $2 R_{1}$ for overtone $2\left(\nu_{1}+\nu_{6}\right)=$ $=3166.2 \mathrm{~cm}^{-1}$, the value is $\Delta \nu_{A}=-5.8 \mathrm{~cm}^{-1}$. The overtone $2 \nu_{8}=3218.5 \mathrm{~cm}^{-1}$ has the positive anharmonic frequency shift $\Delta \nu_{A}=8.5 \mathrm{~cm}^{-1}$ (see Fig. 4, a), which confirms the strengthening of chemical bonds in the overtone region $2 \nu_{8}$. The abnormally low intensity of the overtone $2 \nu$ in the IR spectrum is also caused by the following. In the region of the Fermi resonance $R_{1}+\nu_{3}$ (Raman spectrum) and resonance $R_{1}+\nu_{9}+\nu_{12}$ (IR spectrum), the large negative values of shifts $\Delta \nu_{A}$ are achieved for low-frequency components associated with the total tone $\nu_{1}+\nu_{6}$ (see insets in Figs. 3, $a$ and 4, $a$ ). In particular, for the Fermi resonance $R_{1}+\nu_{3}$ for the component $\left(\nu_{1}+\nu_{6}\right)+\nu_{3}$, the anharmonic shift is $\Delta \nu_{A}=-5.1 \mathrm{~cm}^{-1}$. For $\nu_{8}+\nu_{3}$, $\Delta \nu_{A}=-1.5 \mathrm{~cm}^{-1}$.

\section{Conclusions}

New principles for the identification of vibrations in the region of Fermi resonances include the analysis of half-widths $\delta \nu$ of composite spectral components and their anharmonic shifts $\Delta \nu A$ together with the analysis of intensities for a wide variety 
of Fermi resonances, including abnormally low overtone intensities in "forbidden" vibrational bands. In the case of uniform broadening of the vibrational bands, as evidenced by their Lorentzian shapes, the half-widths of the spectral components $\delta \nu$ are determined by nonlinear vibrational relaxation mechanisms, when high-frequency vibrations are parametrically converted into two or more vibrational modes of lower frequencies. Therefore, the total tones with the participation of $\nu_{1}+\nu_{6}$ or their multiplicates correspond to large values of $\delta \nu$, as well as large values of anharmonic shifts $\Delta \nu_{A}$. In the higher-frequency region of the IR spectrum, complex multiwave FRs are observed, whose existence enhances the nonlinear resonance interaction of vibrational modes. Many Fermi resonances form a kind of a "ladder" between the vibrational and electronic states, which leads to the strengthening of the vibration-electron interaction.

1. J.E. Bertie, C.D. Keefea. Infrared intensities of liquids XXIV: Optical constants of liquid benzene-h6 at $25{ }^{\circ} \mathrm{C}$ extended to $11.5 \mathrm{~cm}^{-1}$ and molar polarizabilities and integrated intensities of benzene-h6 between 6200 and $11.5 \mathrm{~cm}$ 1. J. Mol. Struc. 39, 695 (2004).

2. P.C. Painter, M.M. Coleman, J.L. Koenig. The Theory of Vibrational Spectroscopy and its Application to Polymeric Materials (Wiley-Interscience, 1982).

3. N.E. Kornienko, V.I. Maly, G.V. Ponezha, E.A. Ponezha. Nature of the frequency-angular radiation patterns during stimulated Raman scattering in liquids. Reports of the Academy of Sciences of the USSR, Ser., A 4, 65 (1983) (in Russian).

4. N.E. Kornienko, V.I. Maly, G.V. Ponezha, E.A. Ponezha. Anti-Stokes Raman scattering on polarons in liquids, stimulated by Raman scattering. Opt. Spectr. 60, 1171 (1986) (in Russian).

5. N.E. Kornienko, V.I. Maly, G.V. Ponezha. Generation of excited vibrational states during stimulated Raman scattering and the polariton relaxation mechanism in liquids. Opt. Spectr. 61, 174 (1986) (in Russian).

6. N.E. Kornienko. Observations of the longitudual and transverse splitting in the Raman spectra of liquid chloroform. Ukr. J. Phys. 46, 546 (2001).

7. N.E. Kornienko. Low-frequency collective modes of water hydrogen bonding system. Ukr. J. Phys. 47, 361 (2002).

8. N.E. Kornienko, O.V. Krut. Observations of lattice modes of liquid CS2 in region of total vibrational IR bands. Bulletin of the University of Kiev, Ser. Phys. Math. Sci. 345 (2005) (in Ukrainian).

9. N.E. Kornienko, V.F. Gaiduk, V.I. Maly, G.V. Ponezha. Excitation of overtons of vibrational excitations by stimulated Raman scattering in self-focusing liquids, polariton relaxation mechanism and measurement of vibrational an- harmonicity. In: Optical Spectroscopy (Institute of Physics of the NASU, 1993), p. 171 (in Russian).

10. V.N. Denisov, B.N. Mavrin, V.B. Podobedov, H.E. Sterin. Hyper-Raman scattering of polaritons in liquid carbon tetrachloride. Letters to JETF 35, 312 (1982) (in Russian).

11. V.N. Denisov, B.N. Mavrin, V.B. Podobedov, H.E. Sterin. Hyper Raman scattering and selection rules by wave vector and matrix element in the vibrational spectra of glasses and liquid. JETF 84, 1266 (1983) (in Russian).

12. N.E. Kornienko, S.Yu. Kutovyi, O.V. Piddubetska, N.P. Smoljar. Collective vibrational modes of hydrogen bonding mesh as an indicator of water conditions in vegetable juices and leaves. Bulletin of the University of Kiev, Ser. Phys. Math. Sci., 367 (2003).

13. N.E. Kornienko, S.Yu. Kutovyi, O.V. Piddubetska, N.P. Smoljar. The collective vibration modes of hydrogen bonds as a gauge of water states in fruits and leaves. Biopolymers and Cell 22, No. 1, 49 (2006) (in Russian).

14. N.E. Kornienko. On the relation of the melting heat of crystals with the energies of optical phonons. Bulletin of the University of Kiev, Ser. Phys. Math. Sci. No. 4, 466 (2004).

15. N.E. Kornienko. About phonon discretion of boiling heat. Bulletin of the University of Kiev, Ser. Phys. Math. Sci. No. 3, 520 (2005).

16. V.S. Butylkin, A.E. Kaplan, Y.G. Hronopulo, E.I. Yakubovich, Resonant Interaction Light with Matter (Nauka, 1977) (in Russian).

17. N.E. Kornienko. Spatial evolution of wave amplitudes, stability of solutions and bifurcations in the generation of total and difference frequencies under two-photon resonance. Quant. Electr. 12, 1595 (1985).

18. N.E. Kornienko, S.I. Mikhnytsky. Wave illumination of a substance and high-efficiency generation of radiation by stimulated Raman scattering on polarons. Ukr. J. Phys. 47, 726 (2002).

19. N.E. Kornienko. Effects of strong phonon-electron interaction 1. Finding of new bands of electronic type. Bulletin of the University of Kiev, Ser. Phys. Math. Sci. No. 3, 489 (2006) (in Ukrainian).

20. N.E. Kornienko, V.I. Grygoruk, A.N. Kornienko. Phenomena of nonlinear compression and vibrational instability of condensed media (development of the basics of nonlinear quantum physics). In: Actual Problems of Solid State Physics (Minsk Univ., 2011) Vol. 1, p. 26 (in Russian).

21. N.E. Kornienko, A.P. Naumenko. Collective nature of chemical bonds in fullerenes and fullerites $\mathrm{C}_{60}$ : Vibrational resonances, vibrational-electronic interactions, and anomalous enhancement of bands in the vibrational spectra of nanofilms. In: Chemical Functionalization of Carbon Nanomaterials: Chemistry and Application, edited by V.K. Thakur and M.K. Thakur (CRC Press, 2015), pp. 103-145.

22. N.E. Kornienko, N.P. Kulish, S.A. Alekseev, O.P. Dmytrenko, E.L. Pavlenko. Fine band structure of the vibrational spectra of fullerite $\mathrm{C}_{60}$ and enhancement of intermolecular interaction in high-temperature phase. Opt. Spectr. 109, 742 (2010).

ISSN 2071-0194. Ukr. J. Phys. 2020. Vol. 65, No. 6 
23. M.E. Kornienko, M.P. Kulish, S.A. Alekseev, O.P. Dmitrenko, E.L. Pavlenko, Fine structure of bands in vibrational spectra of $\mathrm{C}_{60}$ fullerite. Ukr. J. Phys. 55, 732 (2010).

24. R. Ananthakrishnan, The Raman spectra of some organic liquids under high dispersion and resolving power. (Benzene, toluene, phenol, chlorobenzene, pyridine and cyclohexane). Proc. Ind. Acad. Sci. A 3, 52 (1935).

25. L.M. Sverdlov, M.A. Kovner, E.P. Krainov. Vibrational Spectrum of Polyatomic Molecules (Nauka, 1970) (in Russian).

Received 25.12.19

М.Є. Корнієнко, О.Л. Павленко

МНОЖИННІ РЕЗОНАНСИ

ФЕРМІ У РІДКОМУ БЕНЗОЛІ

$\mathrm{P}$ е $з$ ю м е

Вперше систематично вивчено ряд взаємопов'язаних коливальних резонансів Фермі (РФ) з їх множини, що спо- стерігаються в рідкому бензолі. Детально проаналізована спектральна структура коливних смуг в спектрах IЧпоглинання і раманівського розсіяння з їх чисельним розкладом на окремі компоненти. Встановлено ускладнення резонансів коливань зі зростанням їх порядку шляхом перекриття різних РФ і появи додаткових резонуючих коливних мод. Для уточнення ідентифікації коливань в основному РФ бензолу $\nu_{1}+\nu_{6}, \nu_{8}$ і корекції частот ряду неактивних коливань, включно із $\nu_{13}\left(E_{1 u}\right)$, проведено порівняння результатів експерименту з даними квантово-хімічних розрахунків. 3 огляду на колективно-хвильові властивості коливних мод у рідкому стані речовини, запропонована розширена концепція аналізу множин РФ, що включає вивчення: 1) змін інтенсивностей різних спектральних компонент у смугах ІЧ поглинання і раманівського розсіяння в коливних смугах РФ різних порядків; 2) напівширин $\delta \nu$ і 3 ) ангармонічних зсувів $\Delta \nu A$ різних компонент у коливних смугах множин РФ. 